\title{
Construction and Operation Mechanism of Peer Teachers' Online Learning Community for Professional English
}

\author{
LIU Zhongwen, WEI Li \\ Liaoning Police Academy, Dalian, China
}

\begin{abstract}
The paper aims to realize professional English teachers' life-long learning and continuous self-improvement through constructing Peer Teachers' Online Learning Community for Professional English, Sharing \& Improving, creating good circular system in teaching, learning and researching under the network environment. Three operational mechanisms are elaborated on in detail, which include multiple, and cooperative interaction mechanism, teaching resources sharing mechanism, problem discussion and evaluation mechanism. Apart from the detailed illustration of three mechanisms, the paper also gives the good example of its application into Sharing \& Improving QQ Group activities.
\end{abstract}

Keywords: Mechanism, Online Learning Community, peer teachers, professional English, Sharing \& Improving

\section{INTRODUCTION}

The teachers' education informatization has become the hot issue of many countries thanks to the widespread application of information technology into educational fields. The special initiatives in accordance with the teachers' teaching demands to strengthen teaching practice and academic research with the assistance of information technology have become the vital approach to realize teachers' learning and professional development. Under the digital background of Web 2.0, the radical change in learning concept and learning patterns is overwhelmingly unstoppable. The platform, with contribution as its core value, greatly expands the learning range of E-learning in order to realize teacher informatization and the life-long learning concept by means of network and socialization.

The popular use of QQ Group software of Tencent, micro blog, micro information and Cloud Computing, and the founding of Renren network and Wiki, provide the learning space for collective interaction. All these resources can be moved back and forth breezily on the public webpage or personal webpage. English teachers and students learning English from different regions and colleges with the common educational backgrounds, aspirations and interests gather together in this limited learning domain, from individual learning and studying to group learning and studying, to build up an interactive learning space based on sharing and interaction which greatly increases teachers' teaching passions and their self-discipline for life-long learning. Both the steady and continuous development of foreign teaching resources in higher education and inexhaustible driving force of training foreign language skills are closely connected with this transformation of learning pattern.

\section{THEORY FOUNDATION AND CONSTRUCTION PRINCIPLES OF ONLINE LEARNING COMMUNITY: SHARING AND IMPROVING}

\subsection{The basic connotation of online learning community for professional English}

Online learning community, though there hasn't been a commonly recognized definition till now, mainly refers to the community created by the learners, the learning assistants (including teachers, experts, and tutors) with the definite learning goals on the virtual network environment. [1] The core feature of online learning community is to share the learning resources, learning experiences and scientific results under the network environment among the community members through communicating with each other frequently with the purpose of fulfilling the common learning goals and forming a kind of interactive interpersonal relationship. [2]Teachers' Online Learning Community for Professional English is a concrete application of online learning community, which aims to establish a virtual learning community with ESP teachers and their students. The functions of this special community are manifested in the following three areas: cognitive information support, interpersonal support, and common development. [3] The community members can obtain updated knowledge information from group sharing or other members' contribution; besides, members can also improve their power of reflection, constructing their new thoughts through active sharing and common solutions to the problems. The online learning community members can keep up close contact through regular online communication, forming an interactive interpersonal relationship to promote mutual understanding and raise awareness and responsibility for the community. The sense of belonging and recognition can be met, which helps arouse learners' passion for study and increase the extent of learners' involvement in learning [4] Through open discussion, multi-sided 
collaboration and interactive communication, community members can tackle learning difficulties and share successful experiences, which contributes to common development and continuous research.

\subsection{The construction principles of peer teachers' online learning community}

In order to promote knowledge sharing and innovation among peer teachers, realizing teachers' knowledge appreciation and value maximization, peer teachers' online learning community for professional English has to adhere to the following two principles from the perspective of knowledge management. [5]

The principle of knowledge accumulation: the accumulation of knowledge quality and quantity id the premise and foundation of peer teachers' online learning community. First of all, this community should display its open character including management concept and range of activity to absorb all of the knowledge resources. Secondly, it requires that the knowledge be digested and stored in sequence. As a result, the community should set up the rigid standards to construct the proper resources, updating the knowledge frequently to meet the requirements of English teaching. Finally, it has to establish the system of individual knowledge accumulation. The peer teachers are encouraged to take active part in sharing and developing of teaching resources according to the establishment of encouragement and restraint.

The principle of value creation: the knowledge obtained by the creative development can maintain the competitive power of the organization. Likewise, the central point of online learning community is value creation. The peer teachers serve as the micro subjects of community creation, so they have to be paid great attention to give the community's creative function into full play. To respect peer teachers' individual demands, to make an attempt at humanized management, to explore their covert knowledge, and to lead them to join in nuclear interaction. All these creative strategies can be applied to the operation of online learning community, and only in this way can the community be fully motivated to reveal its infinite creativity in teaching research.

\section{CONSTRUCTION AND OPERATION MECHANISM OF ONLINE LEARNING COMMUNITY: SHARING AND IMPROVING}

\subsection{Construction of Teachers' Online Learning Community for Professional English: Sharing \& Improving}

On the basis of the previous English QQ Group (Growing-up Group) among 8 English teachers and 82 students built on April 6th, 2012, the author established the second English group entitled with Sharing and Improving on Oct. 19th, 2013, which is expected to be composed of 10 English teachers as its main body and 20 excellent English students at least passing CET 4 as the assisting part. Figure 1 shows its initial construction and activity. These English teachers who have been teaching on the front for almost 20 years with abundant teaching experiences and special education ideas come from different provinces and universities, such as Liaoning Normal University, Bohai University, Taiyuan University of Science and Technology, and Chuxiong Normal University as well. Two of them have been invited to Canada to do relative research into Canadian education, and thus, they can convey updated educational information of the modern countries. For those other young teachers, they have great passions for English teaching. These group members can create the thick atmosphere for English education and research. As to 20 students, they were selected from the previous Growing-up Group through good-friend invitation system and teachers' introduction. All these student members are good at English with good remarks and creative ideas about English teaching styles. They also come from different universities or colleges, such as Nanjing Normal University, Dalian Medical University, Chuxiong Normal University, Bohai University, etc.

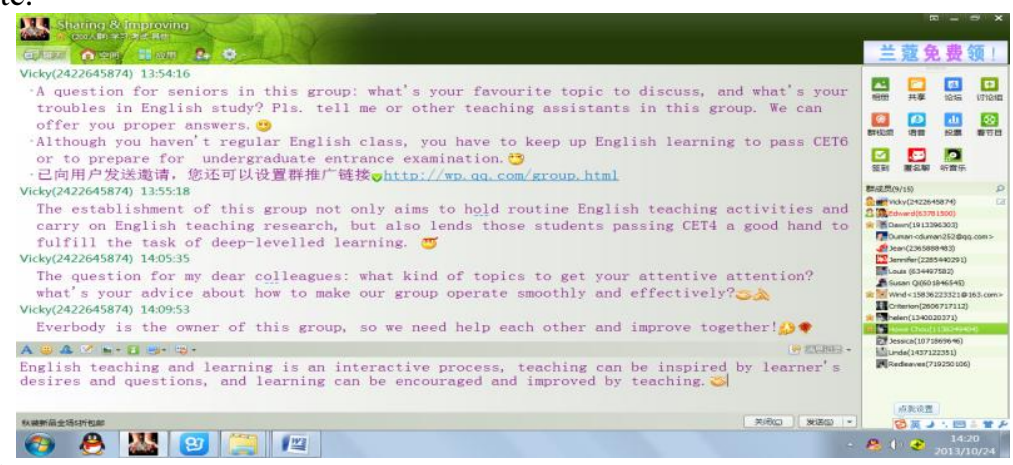

Fig. 1: The initial stage of constructing Sharing \& Improving Online Learning Community

32. Basic operation mechanisms of Sharing and Improving Online Learning Community

According to the original plan, there are three basic operation mechanisms in this community involving interaction mechanism, sharing mechanism, and problem discussion and evaluation mechanism.

The interaction mechanism model: this learning community among teachers and students aims to establish multiple and cooperative mechanism according to the inter-subjects theory. In the construction part, we have known there are 10 English teachers and three of them are professional English experts and scholars in the area 
of Canadian multicultural education, Foreign Language Teaching who can provide constructive suggestions and creative ideas about how to improve our educational concepts and better our teaching styles. Other 7 teachers are the core members in this group who take active part in online teaching research and write valuable papers according to the group discussion and activities, which helps to promote further research into English teaching. They not only absorb those experts' suggestions and directions, but also interact with other peer teachers about their teaching experiences, teaching patterns and strategies. 20 student members are good assistants who can discuss with their teachers, offering their points of views about English teaching directly in this group, which will bring about the radical change of English teaching pattern to adapt to the present education reality. Figure 2 gives us a clear component of multiple members in this group.

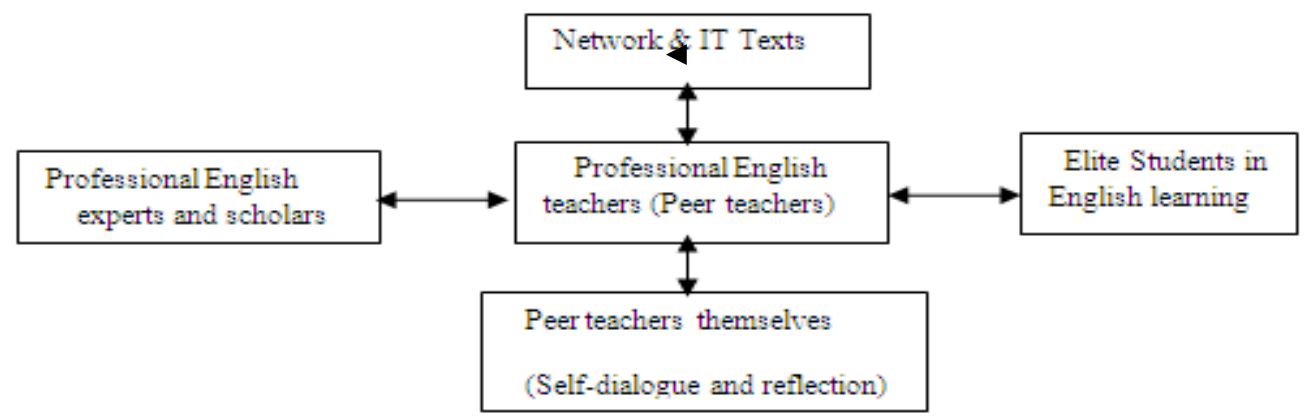

Fig. 2: The multiple and cooperative interaction mechanism model in Sharing \& Improving

The teaching resources sharing mechanism: the peer teachers' online learning community for professional English aims to establish a multi-leveled sharing mechanism according to teachers' personal teaching practice and good research results. They can share teaching practice and cases through electronic teaching plans, open-class videos and their evaluation materials and videos; they can share teaching reflections through individual blogs, QQ Space, or experts' forums; they can share teaching materials of policing English including such majors as investigation, public security administration, criminal and scientific technology, justice administration, Elite Police English, etc. Figure 3 displays its detailed sharing patterns in four areas.

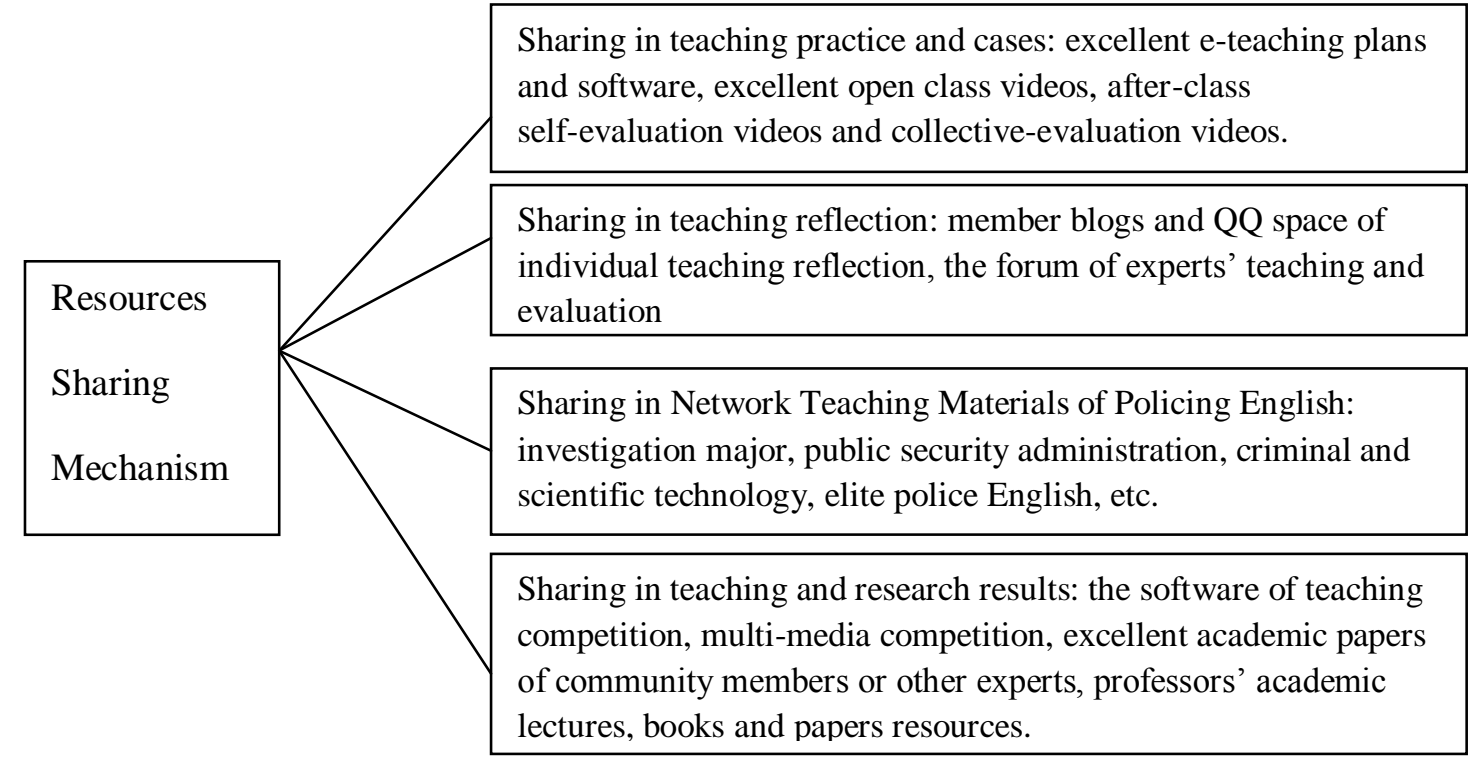

Fig. 3: The teaching resources sharing mechanism in four areas of sharing

The problem discussion and evaluation mechanism: peer teachers led by the group leader Vicky carry out regular multi-lateral teaching and research activities. Every community member regardless of teachers and students can put forward any kind of question concerning English teaching and learning. Once the question is advanced, community members take active part in discussing the question, giving their opinions and solutions to the problem. After one-week or two- week discussion and deep-leveled thinking, the group leader will come to a conclusion through combining all the ideas together, offering the final proper answer. On solving the previous question, the new question will come up immediately, and the community members will carry out the new round of discussion and exploration, which provides the new ideas and strategies for the future teaching practice and 
research. Figure 4 depicts the six processes of problem discussion mechanism in detail and Figure 5 is the practical application of this mechanism through Sharing \& Improving QQ Group activities.

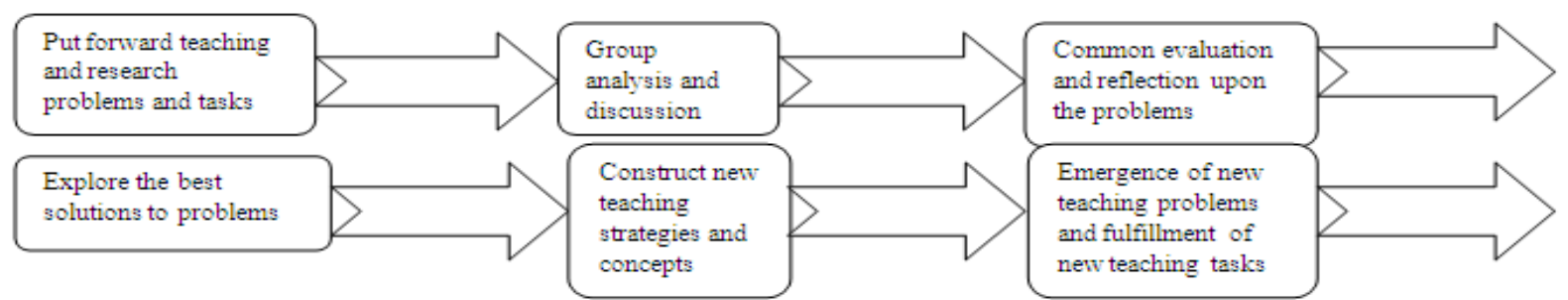

Fig. 4: The problem discussion and evaluation mechanism in six processes

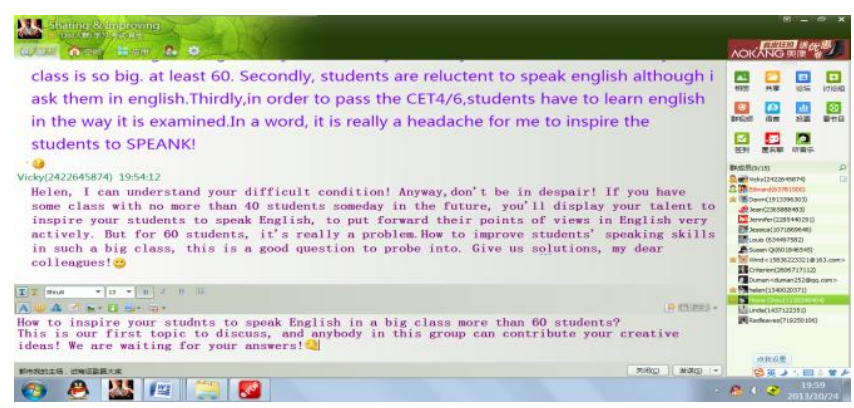

Fig. 5: The application of problem discussion and evaluation mechanism in Sharing \& Improving activities

\section{CONCLUSION}

The original idea of establishing the peer teachers' online learning community is to create the thick research atmosphere among English teachers of professional English to explore proper and practical English teaching patterns and expand the range of English teaching research. This is a sharing and improving space where every community member can obtain huge amount of English teaching and learning resources, maintaining good habits of life-long learning and great creativity of self-improvement. After a short period of operation, we found that not all the community members could join in our discussion activities creatively and actively, and they simply serve as the observers, scanning the topic without giving their points of views. This is a kind of passive and negative attitude towards this project, which prevents the further development of this learning community accordingly. Generally speaking, the multiple and interactive mechanism can be restricted into one thirds of the whole members, which greatly decreases the community's values in application and research. In view of the above limitations, the group leader should tackle this tough problem and come up with some beneficial and fresh strategies to attract all of the community members to dive into the English ocean, exploring the meaningful teaching methods and advancing innovative solutions to the teaching problems.

\section{ACKNOWLEDGEMENTS}

The research is financed by The Twelfth Five-year Plan for Educational Science project of Liaoning Province (2013) No. JG13EB053: On the Operation Mechanism of ESP Teachers' Online Learning Community, the Philosophical Social Science project of Liaoning Province (2012) No. L12DFX035: On Law Enforcement Ability Construction concerning Foreign Police Affairs in Large-scale Activities, and the Foreign Language Reform Project of Liaoning Higher Education Academy of Liaoning Province (2013) No. WYYB13177: A Study of Online Four-dimension Assessment Mechanism and Training Approach of College English Writing.

\section{REFERENCES}

[1] Zhang Jianwei, On-line learning community [DB/DL]. http://www.being.org.cn/theory/netgtt.htm, 2011-02-13.

[2] WEI Li, Construction of Seamless English Language Learning Cyberspace via Interactive Text Messaging Tool [J]. Theory and Practice in Language Studies, 2012 (8): 1590-1596.

[3] WEI Li, Theory and Practice of Online Learning Community's Creation and Application by Means of $Q Q$ Group Software [J]. Internal Journal of Emerging Technology and Advanced Engineering, 2012, (10):42-46.

[4] Kuang Shanyun, Creation of Online Learning Community [J]. Open Education Research, 2005, (4):33-35.

[5] Tang Ruqian, The Construction of Teacher Network Learning Konwledge Community Model [J]. China Educational Technology, 2012 ,(11):82-85. 